\title{
WILL SERVICESCAPE AFFECT PATIENTS' TRUST? THE MODERATING EFFECTS OF PUBLIC AND PRIVATE PATIENTS
}

\author{
Kien Fong $\mathrm{Ng}$ \\ Faculty of Business, Multimedia University, Jalan Ayer Keroh Lama, Melaka, Malaysia \\ jeff.fongng@gmail.com \\ Yee Yen Yuen \\ Faculty of Business, Multimedia University, Jalan Ayer Keroh Lama, Melaka, Malaysia \\ yyyuen@mmu.edu.my \\ Khong Sin Tan \\ Faculty of Business, Multimedia University, Jalan Ayer Keroh Lama, Melaka, Malaysia \\ kstan@mmu.edu.my \\ Jalal Rajeh Hanaysha \\ DRB-HICOM University of Automotive Malaysia Pekan Malaysia \\ jalal@,dhu.edu.my \\ Davoud Nikbin \\ Faculty of Business, Sohar University, Sohar, Oman \\ DNikbin@soharuni.edu.om \\ Kim Piew Lai * \\ Faculty of Business, Multimedia University, Jalan Ayer Keroh Lama, Melaka, Malaysia \\ kplai@mmu.edu.my, *Corresponding author
}

\begin{abstract}
This research examines 1) the relationships between the servicescape and patients' trust in Malaysia; and 2) whether public and private patients moderate the relationships between the servicescape and trust. 400 out-patients, as respondents, were intercepted in the hospitals. The findings show that ambient condition is the significant predictor of patients' trust. However, design, signs and symbols conditions are not the good predictors of patients' trust. Public and private patients view some differences in the sign and symbols condition, while no differences in the ambient and design conditions. The study further discusses and suggests practical implications for management.
\end{abstract}

Keywords: service credibility, revisit intention, decision convenience, affective commitment, hospital

\subsection{Introduction}

Quality of service delivery is the foremost strategic factor that builds and maintains competitive advantages in every industry. With every passing day, customers desire more than just a fair quality product and service, increasingly, customers wish to receive a good quality service in a comfortable environment. The healthcare industry is a unique industry, and the recent enacted National Healthcare Policy has impelled the development of Malaysia's hospitals (Ministry of Health Malaysia, 2016). Studies suggested that the significance of servicescape may contribute value, strengthen competitiveness and enhance differentiation in what customers stand for (Sivasampu, Lim and Hisham, 2013).

Servicescape refers to the physical environment, that is designed to complement and enhance the differentiation of a product or service (Amin, Wahid and Ismail, 2016). Previous studies have suggested that the value of a service can be manifested by enhancing the customers' favourable experience and positive perception through servicescape dimensions, ambient condition (AC), design condition (DC) and signs and symbols condition (SSC) (Amin et al. 2016), which in turn can influence customers' trust (Leister, 2014). Creating favourable responses has become a significant marketing 
goal for many industries, thus a comprehensive interaction among servicescape and trust is important for realizing the long-term relationship between the service providers and customers.

Although the relationships between the servicescape and trust have been investigated in previous studies (Hooper, Coughlan, \& Mullen, 2013; Leister, 2014), very little is known about their interaction in a hospital setting. This is because the understanding about hospital environment is still in its infancy stage, and most studies do not investigate the difference between public and private patients' perception (Amin et al., 2016; Holder \& Berndt, 2011). Thus, in this vague comprehension, an indepth investigation of public and private patients as the moderator will add insights to the knowledge of servicescape.

The purpose of this research is to enhance the knowledge about the servicescape in Malaysia's hospitals and to examine the possible effects of hospital servicescape conditions on patients' trust. Specifically, this study focuses on how the three servicescape conditions relate to patients' trust, with an emphasis on the moderating role of types of patients. Accordingly, the objectives of this research are to examine: (a) the relationship between servicescape conditions and patients' trust, (b) the moderating role of public and private patients.

\subsection{Literature Review}

\subsection{Servicescape}

Bitner's (1992) servicescape model is the most adopted (Lin, Leu, Breen and Lin, 2008) and this model is comparatively straightforward yet comprehensive for capturing behavioural responses of the interaction with environmental stimuli. Rosenbaum and Massiah (2011) suggested that servicescape determines consumers' cognitive and affective processes because most often consumers will interact with the environment first, and then only with the employees. Such a comprehensive model is important to any service provider because it determines the significance of the environment that is able to provide favourable experiences to consumers (Leister, 2014).

Servicescape had been studied in many service industries and had recognized as an important factor in human behaviour (Lai, Chong, Ismail and Tong, 2014). The literature highlights the significant of servicescape, suggesting it as an alternative marketing strategy. It enhances the level of satisfaction and stimulates also the consumers' positive behaviour (attitude, trust, loyalty and intention) (Lai, Chong, Ismail and Tong, 2015), reputation and sales profits (Heung and Gu, 2012).

A typical servicescape model consists of three conditions (Bitner, 1992). The first condition is AC and is referred to the intangible characteristics of the environment that stimulate the individual's senses. Consciously, consumers will perceive a particular subject according to their senses, but they will also unconsciously gauge the organisation's performance based on the ambient condition of a premise (Lai et. al., 2014). This implies that the ambient condition helps the organizations to develop a good first impression.

The second condition, DC, is determined by performance about the organised arrangement of the equipment or facilities in the building. Customers need to use certain facilities and will respond negatively when the equipment does not perform in accordance with expectations (Siu, Wan, \& Dong, 2012). For example, the common facilities in a building that are most often used by customers are the toilets and lifts. Customers will respond negatively and emotionally, especially when those facilities were shut down and had caused them the state of inconvenience.

The third condition is SSC, which refers to the means that the provider uses to direct customers to the desired areas. SSC helps the customers navigate to their destination without the barriers of language, culture and religion (Kusumarini, de Yong and Thamrin, 2012). Customers that come from different locations, without a common language and culture will promote some communication problems. How well the provider helps consumers find their way to the destination in the first place without confusion will have an effect on customers' interest in returning to the service area.

\subsection{Patients' Trust}

Trust, is defined as the confidence of a person, leading him/her to have faith in the other party (Alrubaiee and Alkaa'ida, 2011). In other words, trust refers to people not displaying negative behaviour because of the strong relationship between the service provider and customers. Trust will only be built when the expectations of customers are met by the provider. Trust allows people to transact business under favourable circumstances (Suki, 2011).

In healthcare, trust plays an important role in connecting the patients and the providers. It provides comfort to the patients which, in turn, improves the efficiency and effectiveness of the medical services. A trust relationship is especially important to minimize the cognitive risks and maximize the 
security perceptions in patients (Suki, 2011). When a trust relationship is established, it forms a basis for future collaborations.

In terms of servicescape, Holder and Berndt (2011) stated that AC provides comfortable surroundings for patients to wait or rest. Specifically, patients show approachable behaviours and having trust in the hospital when facilities and physical surroundings are well maintained. In addition, hospitals have to do much detail planning in the arrangement of the equipment and layout design, as it is a service centre that accommodates a large number of patients every day (Holder \& Berndt, 2011). Messy or narrow walkways will foster distrust in patients, leading them to have a fear of discomfort and insecurity. Most often, a hospital is designed with a large waiting and walking area in order to adapt to the overcrowding of patients. Signs and symbols condition plays an important role in the navigation system, especially in a large waiting and walking space (Rousek and Hallbeck, 2011). Patients will not hesitate to enter the hospital when there is an apparent navigation system to direct them. Patients will not get frustrated or will not decrease their trust in the hospital when they get can reach the designated areas in time. Leister (2014) further illustrated that, when patients feel a pleasant sensation in a welldesigned environment, that will enhance their ability to trust the facility.

H1: AC affects the patients' trust.

H2: DC affects the patients' trust.

H3: SSC affects the patients' trust.

\subsection{Public patients and private patients as the moderator}

Although numerous studies on patients' perceptions in healthcare institutions (Yogesh \& Satyanarayana, 2014), empirical evidence examining the influence of servicescape is limited (Debajani Sahoo \& Ghosh, 2016). Further examination of servicescape, for example, in the studies of Lin, Leu and Breen (2008), suggested that servicescape that enhances patients' favourable behavioural responses may vary, depending on patients' experience. This implies that patients may develop different perceptions on servicescape depending on where they engage the healthcare service, i.e. public hospital or private hospital.

Given that, public and private hospitals may fit together as a part of an integrated system, they are different in term of operational strategies and management, which in turn lead to different perceptions towards the hospitals. As such, understanding the possible effects of interaction between public patients and private patients may contribute important insights to the knowledge of servicescape. Nonetheless, only a few studies have offered insights into such issues as how patients respond to two different types of - public and private - hospitals (Aliman and Mohamad, 2013). Most of the past researchers studied the influences of servicescape either in public patients or private patients alone (Azila-gbettor, 2013), thus, is has become elusive how the servicescape thrives in different types of patients. This pressing problem raises questions about the understanding of patients' perceptions towards public hospitals and private hospitals. In other words, the purpose of this study is to investigate the servicescape model in two different contexts, public patients and private patients.

\subsection{Methodology}

A set of questionnaire was adopted to examine the constructs with 5-point Likert-type scales, and they were integrated into Figure 1. Trust towards hospitals was assessed by 4 questions based on a study by Koufaris and Hampton-Sosa (2004). To examine the relationship between servicescape and trust, we borrowed the questions of ambient condition (11 questions) and design condition (9 questions) from the studies of Siu, Wan and Dong (2012) and Azila-Gbettor (2013), while the assessment of signs-andsymbols condition (6 questions) from the work of Siu, Wan and Dong (2012) and Kusumarini, de Yong and Thamrin (2012).

H4: Types of patients moderate AC $\rightarrow$ Patients' Trust.

H5: Types of patients moderate DC $\rightarrow$ Patients' Trust.

H6: Types of patients moderate SSC $\rightarrow$ Patients' Trust. 


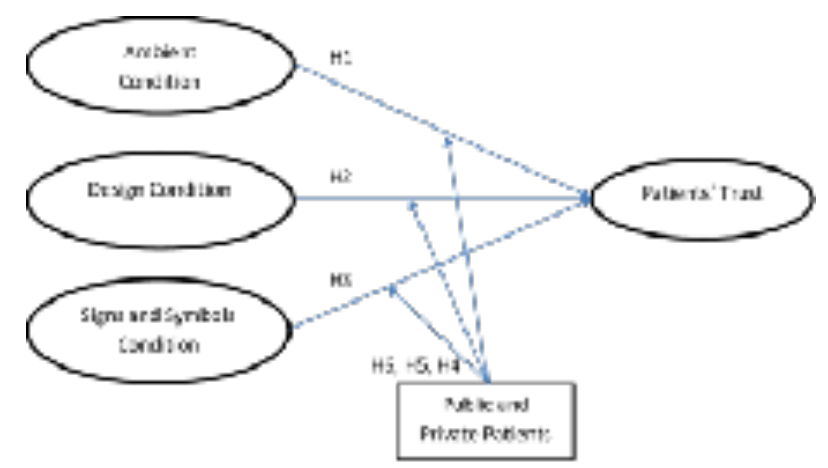

Figure 1: Research Framework

\subsection{Data Collection}

In order to lend a set of reliable scales, a pilot test was conducted on 50 patients in both public and private hospitals in Kuala Lumpur. The outcome of the pilot test suggested that all the constructs had an adequate reliability coefficient, i.e. the patients' trust, $\mathrm{AC}, \mathrm{DC}$ and $\mathrm{SSC}$ were recorded as 0.747 , $0.798,0.809,0.832$ and 0.758 , respectively.

Subsequently, a mass sample of 400 out-patients were collected from public and private hospitals in three different states in Malaysia, namely Kuala Lumpur, Johor Bahru and Penang. Those states represented the three largest urban areas in Malaysia (Shivaji, 2015), and because those states have high population density, they may present the greatest demand of healthcare admissions in Malaysia (Sivasampu et al., 2013). We divided equally the respondents between public and private patients, with 200 from each.

The demographic profile of the respondents showed $54 \%$ female $(n=108)$ and $46 \%$ male $(n=92)$ from public hospitals, while from private hospitals were $57 \%$ female $(n=114)$ and $43 \%$ male $(n=86)$. In terms of ethnicity, the public and private patients had a similar proportion: Malay (67.5\%), Chinese $(24.5 \%)$ and Indian (8\%). Kuala Lumpur contributed the highest percentage of respondents $(70 \%)$, followed by Johor Bahru (17\%), and Penang (13\%). Regarding respondents' average income per year, public patients represented the income ranges below RM25,000 (43\%) and no income (29\%). Likewise, private patients represented the income ranges of RM51,000-RM75,000 (41.5\%) and RM26,000-RM50,000 (30\%). 51\% of the public patients had been visiting the hospitals for more than 3 years, while $39.5 \%$ of private patients had been visiting the hospital more than 2 years.

\subsection{Results}

\subsection{Confirmatory Factor Analysis}

We used Analysis of Moment Structure (AMOS) version 24 to analyse the data. We followed Hair et. at.'s (2010) suggestion and performed two levels of analysis via Confirmatory Factor Analysis (CFA) and Structural Equation Modeling (SEM). CFA was applied in this research to assess the goodness-offit of the proposed model. Misfit items were identified and removed from further analysis, i.e. items with less than 0.50 factor loading and cross loading. The final $\mathrm{AC}$ construct had 4 items (factor loadings of $0.708,0.891,0.926,0.920)$; DC with 4 items $(0.846,0.881,0.834,0.770)$; SSC with 4 items $(0.787,0.898,0.893,0.783)$; and Trust with 4 items $(0.689,0.848,0.836,0.769)$. Table 1 showed the value of discriminant validity and convergent validity of the model with the constructs' AVEs exceeded 0.50 (Hair, 2010) and greater than the square correlation coefficient involving the constructs (Voorhees, Brady, Calantone and Ramirez, 2015).

The fit of the model showed a satisfactory goodness-of-fit $\left(X^{2}=269.764 ; \mathrm{df}=160 ; \mathrm{p}<0.001\right.$; GFI $=0.936$; AGFI $=0.916$; $\mathrm{CFI}=0.980$; IFI $=0.980$; NFI $=0.953$; TLI $=0.977$; RMSEA $=0.041$ ). All the model fit indexes, supported the adequacy of the model to identify the influences of servicescape on patients' trust.

Table 1: Constructs' Reliability (CR), AVE and Squared Correlation Coefficient 


\begin{tabular}{|c|c|c|c|c|c|c|c|}
\hline & Mean & SD & $\mathrm{CR}$ & 1 & 2 & 3 & 4 \\
\hline 1.Anubint (ondition (AC) & 3.368 & 0.891 & 0.922 & 0.750 & & & \\
\hline 2. Desien Condition (DC) & 3.501 & 0.873 & 0.901 & 0.159 & 0.694 & & \\
\hline 3.Signs und Symbols Condition (SSC) & 3.351 & 0.R6s & 0.907 & 0.156 & 0.457 & 0.709 & \\
\hline 1.Paticnts' Trust & 3.714 & $0.73 \mathrm{l}$ & 0.867 & 0.253 & 0.078 & 0.095 & 0.621 \\
\hline
\end{tabular}

"Diagunal - AVE

\subsection{Structural Model}

A structural equation modelling was built to measure the possible causal effects of servicescape conditions on patients trust. The structural model suggested the fit indexes as follow: $\mathrm{X}^{2}=180.228$; $\mathrm{df}=98 ; \mathrm{p}<0.001 ; \quad \mathrm{GFI} 1=0.946 ; \quad$ AGFI $=0.926 ; \quad \mathrm{CFI}=0.982 ; \quad \mathrm{IFI}=0.982 ; \quad \mathrm{NFI}=0.961 ; \quad \mathrm{TLI}=0.978$; RMSEA $=0.046$ ). The fit indexes suggested the proposed model had a good fit with the data.

We continued with analysing the hypothesises of $\mathrm{H} 1, \mathrm{H} 2$, and $\mathrm{H} 3$, that indicated the influences of servicescape on patients' trust. The results supported $\mathrm{H} 1$ that $\mathrm{AC}(\beta=0.449$, p-value $<0.001)$ had a positive causal effect on patients' trust. On contrary, $\mathrm{DC}(\beta=0.023$, $\mathrm{p}$-value $=0.752)$ and $\mathrm{SSC}(\beta=0.116$, p-value $=0.112)$, showed positive effects but they $(\mathrm{H} 2, \mathrm{H} 3)$ were not significant. This implies that the data support only the H1, causal relationship between the ambient condition and patients' trust.

\subsection{Moderating Effects}

Multi-group analysis procedure was employed to analyse the moderating effect of type of patients (public and private) on the relationship between servicescape conditions and patients' trust. Moderating effect is evident when the beta value of group 1 is significant but the beta value of group 2 is not or when the beta value of group 1 is significant and positive but the beta value of group 2 is not (Hair et. al., 2010)

We split the data into two groups, i.e. public patients as group 1 and private patients as group 2 and performed the multi-groups model procedure based on Hair et. al. (2010). The results indicated that the relationship between $\mathrm{AC}$ and trust was not moderated by the type of patients, even though it was the significant predictor of patients' trust. The beta and p-values of public patients $(\beta=0.528, \mathrm{p}$ value $<0.001)$ and private patients $(\beta=0.364$, $p$-value $<0.001)$ were both significant, suggesting $\mathrm{H} 4$ was not supported because they were not different. The DC showed a negative beta value in public patients $(\beta=-0.198, p$-value $=0.117)$ and a positive beta value in private patients $(\beta=0.120$, pvalue $=0.179$ ). However, there was no moderation effect between DC and trust because both beta values were not significant, H5 was not supported. The SSC was the only construct that showed a moderation effect. Its beta value for public patients was 0.258 ( $\mathrm{p}$-value $=0.045$ ), while for private patients, it was 0.053 ( $p$-value $=0.543$ ). This implied that the relationship between SSC and trust was moderated by the type of patients. In overall, this outcome provided support for H6 concerning the moderation role of public-private patients on the relationship between SSC and trust.

Table 2: Moderating Effects of Public and Private Patients

\begin{tabular}{|c|c|c|c|c|}
\hline & & Beta & p-value & Mcderation E.Ysct \\
\hline \multirow[t]{3}{*}{$\mathrm{H} 4$} & $A C \rightarrow$ Patients' Trust & & & \multirow{3}{*}{$\begin{array}{c}\text { Ne noderstion } \\
\text { effoct }\end{array}$} \\
\hline & Public Patient: & 0.528 & $<0.001$ & \\
\hline & Privats Pationts & 0.36 & $=0.001$ & \\
\hline \multirow[t]{3}{*}{ H5. } & $\mathrm{DC} \rightarrow$ Patients' Trust & & & \multirow{3}{*}{$\begin{array}{c}\text { Ne noderation } \\
\text { effest }\end{array}$} \\
\hline & Publie Patien:s & -0.128 & 0.117 & \\
\hline & Privat: Paticnis & 0.120 & 0.179 & \\
\hline \multirow[t]{3}{*}{ H6. } & SGC $\rightarrow$ Patiznts' Trust & & & \multirow{3}{*}{ Mcderation E.rsct } \\
\hline & Public Paticats & 0.258 & 0.045 & \\
\hline & Private Paticuls & 0,053 & 0.543 & \\
\hline
\end{tabular}

\subsection{Discussion}

This research recommends that, apart from the values derived from the quality of product and service, servicescape is essential to build and to sustain positive relationships between the hospital and patients. Specifically, the finding shows that $\mathrm{AC}$ is likely to enhance the patients' trust. When 
differences in the type of patients are considered, the structural model reveals the changes in the relationship between the variables are possible.

Among the three conditions in servicescape examined, AC is the only condition that has a pronounced effect on patients' trust. This finding is consistent with Leister (2014), that suggests physical surrounding of a facility can evoke customers' favourable experiences and lead to positive responses. This suggests that ambient condition has a primary role in forging trust relationship with customers. Hospital management could invest or allocate more resources by implementing health recovery education through beautification of the surrounding environment and adding colour to the exterior walls that could result in a peaceful environment.

The finding strengthens also the application of servicescape in the context of the hospitality industry, given that empirical research investigating the influences of servicescape in this industry is limited. We take note that ambient condition plays an important role in facilitating patients' trust. This insight suggests that besides evoking favourable responses, surrounding environment can influence the trust the patients have in the healthcare service. In view of this, the hospital management could reconsider a better strategic plan and the focus should be on enhancing patients' trust. The plan should also anticipate any potential conflicts that might result in a deep sense of distrust.

In contrast to the studies of Siu, Wan and Dong (2012), we find that design condition has no causal impact on patients' trust. One possible reason is that, unlike other industries, the focus of a hospital is mainly on providing good quality medical services, and it is not from the creative design aspect that is said to attract customers. Most of the hospital built environment has a similar context of design and layout. Instead of creative design, hospital management should manage the spatial arrangement that can result in better movement of patients and employees. This is evident in the studies of Altomonte and Schiavon (2014), suggesting the design aspect of physical surrounding cannot be regarded as a strong condition that could create a sense of belonging for customers.

Even though signs and symbols condition shows a positive relationship, yet it is not significant to predict patients' trust, when considering both public and private patients. This is intriguing and is possible because most patients have visited the hospital for more than two years and they have been exposed to those signs and symbols frequently. Since patients' exposure to this condition has been alleviated, it is possible that they have become familiar with those signs and symbols, and subsequently have reduced their evocation of positive responses. Michelle, Grobler, Strasheim and Orton (2013) stated that signs and symbols may not able to provide essential information to customers. This implies that in a hospital setting, the finding suggests that signs and symbols condition is not the main determinant towards patients' trust. Hospital management should redirect resources to other aspects of servicescape, i.e. ambient condition.

This research suggests also that the negative outcomes concerning the design condition and signs and symbols condition, may due to the fact that a hospital is not a pleasant place for the public to visit except for those who are seeking treatment. In this view, the perception of patients towards servicescape in a hospital setting may not be the same as how ordinary customers perceive servicescape in a pleasurable environment, i.e. hotel, casino and restaurants. Thus, rather than an attempt to provide a favourable experience with the improvement of design, signs and symbols conditions, we suggest that hospital management should strive to ensure the quality of ambient condition.

The moderating effect of the type of patients in the relationships between servicescape conditions and patients' trust has been examined. Interestingly, public patients and private patients have different views regarding the relationship between signs and symbols condition and trust. However, public patients and private patients have no difference in their perceptions in the relationships of ambient condition $\rightarrow$ trust and design condition $\rightarrow$ trust. It can be explained that both types of patients have been visiting the hospital for more than two years, as such those experience may have moderated their perception towards the ambient and design conditions, as such they may view such conditions as the mandatory condition for providing a good healthcare service, for instance, smart air conditioning, standards of layout design and hygiene control. In contrast, in view of the size of hospitals, public patients need more signage to navigate to the direction than private patients. This is in view that most public hospital buildings are larger and bigger than private hospital buildings. As such a proper management of signs and symbols would help to forge patients' positive responses.

\subsection{Limitations and Future Research}

Design, signs and symbols conditions do not appear significant in the current study and have contradicting with previous findings. In particular, the need arises for additional research to investigate 
the design, signs and symbols conditions, identifying how these conditions manifest themselves in the hospital context. Because the comprehension of servicescape conditions remains unclear in the context of the hospital, a logical qualitative research method for this phenomenon is suggested.

New research direction should investigate the mediating effects of patients' attitude in the relationship between servicescape and trust. This is to investigate any existence of indirect relationships between design, signs and symbols conditions and trust, given that those conditions have failed to show any direct effects on trust. The future direction could investigate which conditions patients are most sensitive to it.

The medical staff is the individual who had long-exposure with servicescape conditions than patients. Their perceptions are also important for studying aspects of needed improvement. Thus, future research should consider examining servicescape through the perceptions of medical staff.

Finally, we noted that the data that are collected from three states may not enough to represent the whole Malaysia healthcare centres system. Future research should collect views regarding the interior design of in-house clinics and outsource clinical services.

\subsection{Conclusion}

We propose and test a framework of servicescape in a hospital setting, anticipating three servicescape conditions based on a comprehensive pool of questions. The results show that the framework and scale are reliable and valid. Examining servicescape conditions in a hospital setting is still underdeveloped. More studies are required to seek the understanding of patients' perception of servicescape and trust. This study intends to address and add new insights in the healthcare literature by providing a framework examining the dynamics in a hospital setting. The statistical evidence suggests that ambient condition as a strong predictor of patients' trust may adequately represent the overall Malaysian's perceptions of servicescape in a hospital setting. The proposed framework can be further differentiated with the perceptions of public and private patients. The multi-group analysis suggests that public and private patients view the signs and symbols condition differently. Therefore, the proposed framework may add knowledge in the conceptualisation of servicescape in a hospital setting.

\section{Acknowledgments}

We like to thank the Ministry of Higher Education, Malaysia for funding this research (Fundamental Research Grant Scheme - FRGS/1/2015/SS01/MMU/03/01) and RMC of Multimedia University.

\section{References}

Aliman, N. K., \& Mohamad, W. N. (2013). Perceptions of Service Quality and Behavioral Intentions : A Mediation Effect of Patient Satisfaction in the Private Health Care in Malaysia. International Journal of Marketing Studies, 5(4), 15-29.

Alrubaiee, L., \& Alkaa'ida, F. (2011). The Mediating Effect of Patient Satisfaction in the Patients' Perceptions of Healthcare Quality - Patient Trust Relationship. International Journal of Marketing Studies, 3(1), 103-127.

Altomonte, S., \& Schiavon, S. (2014). Influence of factors unrelated to environmental quality on occupant satisfaction in LEED and non-LEED certified buildings. Building and Environment, 77, $148-159$.

Amin, S. H. M., Wahid, S. D. M., \& Ismail, M. (2016). Observing the Natural Dimension of Hospital Servicescape on Patient Satisfaction. Procedia Economics and Finance, 37(16), 58-64.

Azila-gbettor, E. M. (2013). Physical Evidence and Quality Service Delivery in Public Hospitals in Ghana, 3(4), 153-163.

Bitner, M. J. (1992). Servicescapes: the Impact of Physical Surroundings on Customers and Employees. Journal of Marketing, 56(2), 57-71.

Hair, J. F. (2010). Multivariate data analysis (7th ed.). Pearson Education.

Heung, V. C. S., \& Gu, T. (2012). Influence of restaurant atmospherics on patron satisfaction and behavioral intentions. International Journal of Hospitality Management, 31(4), 1167-1177.

Holder, M., \& Berndt, A. (2011). The effect of changes in servicescape and service quality perceptions in a maternity unit. International Journal of Health Care Quality Assurance, 24(5), 389-405.

Hooper, D., Coughlan, J., \& Mullen, M. R. (2013). The servicescape as an antecedent to service quality and behavioral intentions. Journal of Services Marketing, 27(4), 271-279.

Kusumarini, Y., de Yong, S., \& Thamrin, D. (2012). Signage System of Malls in Surabaya: Universal Interior Design Applications and Suggestions for Solution. Procedia - Social and Behavioral 
Sciences, 68, 515-525.

Lai, K. P., Chong, S. C., Ismail, H. B., \& Tong, D. Y. K. (2014). An explorative study of shopper-based salient e-servicescape attributes: A Means-End Chain approach. International Journal of Information Management, 34(4), 517-532.

Lai, K. P., Chong, S. C., Ismail, H. B., \& Tong, D. Y. K. (2015). Do salient e-servicescape attributes predict online brand image? International Journal of Internet Marketing and Advertising, 9(3), 209-232.

Leister, J. E. (2014). The Hospital Servicescape as an Indicator in the Process of Building Trust within Patient Selection Decisions. Gesundheitsökonomie \& Qualitätsmanagement, 19(6), 272-280.

Lin, B. Y.-J., Leu, W.-J., Breen, G.-M., \& Lin, W.-H. (2008). Servicescape: Physical environment of hospital pharmacies and hospital pharmacists' work outcomes. Health Care Management Review, 33(2), 156-168.

Michelle, C., Grobler, A. F., Strasheim, A., \& Orton, L. (2013). Getting young adults back to church: A marketing approach. HTS Teologiese Studies / Theological Studies, 69(2), 12 pages.

Ministry of Health Malaysia. (2016). Country Health Plan 2011 - 2015. Country Health Plan : 10th Malaysia Plan 2011-2015, 1-95.

Rosenbaum, M. S., \& Massiah, C. (2011). An expanded servicescape perspective. Journal of Service Management, 22(4), 471-490.

Rousek, J. B., \& Hallbeck, M. S. (2011). The use of simulated visual impairment to identify hospital design elements that contribute to wayfinding difficulties. International Journal of Industrial Ergonomics, 41(5), 447-458.

Sahoo, D., \& Ghosh, T. (2016). Healthscape role towards customer satisfaction in private healthcare. International Journal of Health Care Quality Assurance, 29(6), 600-13.

Shivaji, S. (2015). Demographia World Urban Areas - Built Up Urban Areas or World Agglomerations. Demographia World Urban Areas.

Siu, N. Y. M., Wan, P. Y. K., \& Dong, P. (2012). The impact of the servicescape on the desire to stay in convention and exhibition centers: The case of Macao. International Journal of Hospitality Management, 31(1), 236-246.

Sivasampu, S., Lim, T., \& Hisham, A. (2013). National Healthcare Establishment and Workforce Statistics (Hospital) 2011.

Suki, N. M. (2011). Assessing patient satisfaction, trust, commitment, loyalty and doctors' reputation towards doctor services. Pakistan Journal of Medical Sciences, 27(5), 1207-1210.

Voorhees, C. M., Brady, M. K., Calantone, R., \& Ramirez, E. (2015). Discriminant validity testing in marketing: an analysis, causes for concern, and proposed remedies. Journal of the Academy of Marketing Science, 44(1), 119-134.

Yogesh, P. P., \& Satyanarayana, C. T. (2014). The impact of Healthscape on Service Quality and Behavioural Intentions, 2, 18-22. 